\title{
Strategi peningkatan kinerja Sumber Daya Manusia (SDM) pada UMKM di Malang dengan Metode SWOT
}

\author{
Rahayu Puji Suci ${ }^{1}$ \\ Magister Manajemen Program Pasca Sarjana \\ Universitas Widyagama Malang \\ Adya Hermawati ${ }^{2)}$ \\ Magister Manajemen Program Pasca Sarjana \\ Universitas Widyagama Malang \\ Suwarta \\ Agribisnis Fakultas Pertanian \\ Universitas Widyagama Malang \\ Email:wati_wati38@yahoo.com \\ Pepedot87@gmail.com
}

\begin{abstract}
Abstrak
Tujuan - Tujuan dari penelitian ini adalah menentukan strategi pengembangan kinerja sumber daya manusia pada UMKM di Kota Malang melalu implementasti analisis SWOT (Strengths, Weaknesses, Opportunities, dan Treatments).

Desain/Metodelogi/Pendikatan - Penelitian ini menggunakan SWOT analisis. SWOT dapat menjadi alat yang digdaya dan mampu mengeksplorasi kemungkinan-kemungkinan perencanaan strategi baru maupun memulai program yang baru

Temuan - Hasil menunjukkan indikator Strength yang paling tinggi adalah S5 (Pelayanan) yaitu sebesar 4.20. Sementara itu, indikator Weakness yang paling tinggi adalah W4 (Kualitas Sumber Daya Manusia), yaitu sebesar 3.20. Kemudian indikator Opportunity yang paling tinggi adalah O1 (Oleh-oleh khas daerah) dan O5 (Bahan Baku) yaitu sebesar 4. Sementara itu, indikator Threat yang paling tinggi adalah T3 (Pesaing pendatang baru), yaitu sebesar 2.3. Kemudian untuk lokasi titik potong A, B, C, dan D, yaitu titik E, berada kuadran I (Strategi agresif). Dengan demikian, analisis SWOT terhadap UMKM di Kota Malang menunjukkan posisi yang bagus, sehingga dapat diterapkan strategi SO.
\end{abstract}

Kata kunci: SWOT, UMKM, strategi peningkatan kinerja.

\begin{abstract}
Purpose - The purpose of this study is to determine the strategy for developing the performance of human resources at MSMEs in Malang through the implementation of a SWOT analysis (Strengths, Weaknesses, Opportunities, and Treatments).

Design / Methodology / Approach - This study uses SWOT analysis. SWOT can be a powerful tool and is able to explore the possibilities of planning new strategies as well as starting new programs

Findings - The results show that the highest Strength indicator is S5 (Service), which is 4.20. Meanwhile, the highest Weakness indicator is W4 (Quality of Human Resources), which is 3.20. Then the highest Opportunity indicator is $\mathrm{Ol}$ (Regional souvenirs) and O5 (Raw Materials), which is 4. Meanwhile, the highest Threat indicator is T3 (Newcomer Competitors), which is 2.3. Then for the intersection points of $A, B, C$, and D, namely point E, are in quadrant I (aggressive strategy). Thus, the SWOT analysis of MSMEs in Malang City shows a good position, so that the SO strategy can be applied.
\end{abstract}

Keyword: SWOT, SMEs', perfoemance improvement strategy.

Jurnal Manajemen Sains dan Organisas Vol 1, No 1, 2020 pp. $64-74$ FEB UPR Publishing $2685-4724$
Rahayu Puji Suci, Adya Hermawati, Suwarta. Published in the Jurnal Manajemen sains dan Organsasi. Published by FEB UPR Publishing Limited. This article is published under the Creative Commons Attribution (CC BY 4.0) licence. Anyone may reproduce, distribute, translate and create derivative works of this article (for both commercial and non-commercial purposes), subject to full attribution to the original publication and authors. 


\section{PENDAHULUAN}

Lingkungan bisnis saat ini dihadapkan pada dinamika pasar yang sangat kompetitif. Untuk itu, organisasi perlu menghadapinya dengan kemampuan beradaptasi dan agility sehingga mampu mencapai keunggulan kompetitif yang berkelanjutan. Bisnis UMKM di Malang Raya adalah salah satu potensi ekonomi kerakyatan yang sedang dikembangkan oleh Dinas Koperasi dan UMKM di Kota Malang. Hal ini dimaksudkan untuk meningkatkan kesejahteraan masyarakat dengan memberdayakan UMKM. Empat tahap perkembangan UMKM yaitu tahap start-up, growth, expansion, dan going overseas perkembangan UMKM (Suci, 2009; Purnamasari, Suci and Handini, 2013; Suci, 2013; Suci and Priyono, 2013). Untuk Indonesia tahapan ini belum sepenuhnya berjalan dengan baik dikarenakan berbagai hambatan seperti kondisi finansial, sumber modal, teknlogi dan sumber daya manusia (Hadjimanolis, 1999; Erdil and Erbıyı, 2015).

Selain itu, pemerintah Indonesia belum memiliki the role of thumb dari model pembinaan UMKM yang terintegrasi untuk mencapai kinerja yang diharapkan. Dalam artikel ini, teridentifikasi aspek sumber daya manusia merupakan kunci keberhasilan UMKM (Purnamasari, Suci and Handini, 2013; Suci, 2013; Suci and Priyono, 2013).

Tujuan dari artikel ini adalah untuk mengetahui sampai sejauh mana kekuatan, kelemahan, peluang, dan ancaman pengembangan UMKM di kota Malang, sehingga dapat menjadi titik awal untuk menentukan strategi yang sesuai bagi UMKM kota Malang. Maka pada artikel ini, strategi pengembangan SDM diinvestigasi dan dianalisa sehingga dapat dilakukan pemetaan posisi strategis UMKM berdasarkan análisis SWOT. Ringkasan Analisis Faktor Eksternal Strategis (EFAS) dan Ringkasan Analisis Faktor Strategis Internal (IFAS) dipertimbangkan dalam membangun matriks SWOT (Suci and Priyono, 2013).

\section{STUDI PUSTAKA Analisis SWOT}

Teknik perumusan strategi yang dikembangkan oleh (David, 2009) dilakukan melalui tiga tahap pelaksanaan dengan menggunakan matriks sebagai model analisisnya. Tiga tahapan kerangka kerja dimaksud adalah tahap input (the input store), tahap pencocokan (the matching stage) dan tahap keputusan (the decision stage). Terdapat matriks evaluasi faktor eksternal (EFE) dan evaluasi faktor internal (IFE) sebagai inputan dari matrik SWOT. Tabel 1 menunjukkan salah satu contoh matrik pada perumusan strategi, yaitu matrik evaluasi faktor eksternal (EFE).

Tabel 1. Contoh matrik evaluasi faktor eksternal - EFE

\begin{tabular}{|l|l|l|l|l|}
\hline \multicolumn{1}{|c|}{ Faktor-faktor Eksternal } & Bobot & $\begin{array}{c}\text { Peringkat } \\
\text { (rating) }\end{array}$ & $\begin{array}{c}\text { Skor } \\
\text { (bobot x rating) }\end{array}$ & \\
\hline Peluang & & & & \\
\hline 1. & & & & \\
\hline 2. & & & & \\
\hline 3. & & & & \\
\hline$k e-n$ & & & & \\
\hline Ancaman & & & & \\
\hline 1. & & & & \\
\hline 2. & & & & \\
\hline 3. & & & & \\
\hline$k e-n$ & & & & \\
\hline Jumlah & & & & \\
\hline
\end{tabular}

Diadopsi dari (David, 2009) 
Untuk analisis SWOT sendiri, kebanyakan digunakan sebagai evaluasi pada tahap perencanaan misalnya untuk mengevaluasi perencanaan strategi operasi dan supply chain (Fahmy Salama et al., 2009), maupun menganalisis ketrampilan dan pengetahuan Sumber Daya Manusia (SDM) (Amanatidou, 2014). Teknik SWOT seringkali digabungkan dengan metode analisis keputusan seperti AHP (Analytical Hierarchy Process) (Eko Nurmianto, Arman Hakim Nasution and Syafril Syafar, 2004; Erdil and Erbıyı, 2015; Subramanian and Ramanathan, 2012; Anggarani, Mas'ud and Zulkifli, 2017), ANP (Analytic Network Process), maupun F-ANP (Fuzzy Analytic Network Process) (Cengiz Toklu, Erdem and Taşkın, 2016).

Analisis SWOT merupakan singkatan dari Strengths (kekuatan), Weakneses (kelemahan), Opportunity (peluang), dan Threat (ancaman). Analisis SWOT adalah metode yang sesuai untuk menganalisis faktor lingkungan internal organisasi (kekuatan dan kelemahan) dan faktor lingkunga eksternal (peluang dan ancaman) dalam proses perencanaan strategis. Kerangka kerja SWOT dapat menjadi alat strategis yang cukup spesifik dalam menentukan posisi strategis yang sesuai untuk suatu organisasi (Cengiz Toklu, Erdem and Taşkın, 2016). Kerangka dasar analisis SWOT ditunjukkan pada Tabel berikut ini.

\section{Tabel 2. Kerangka kerja dasar} KEKUATAN

KELEMAHAN

\begin{tabular}{c|cc}
\hline PELUANG & $\begin{array}{c}\text { Memperoleh peluang yang } \\
\text { sangat sesuai dengan } \\
\text { kekuatan perusahaan } \\
\text { Memanfaatkan kekuatan } \\
\text { ANCAMAN }\end{array}$ & $\begin{array}{c}\text { Mengatasi kelemahan untuk } \\
\text { memperoleh peluang }\end{array}$ \\
& $\begin{array}{c}\text { Mencegah kelemahan agar } \\
\text { untuk mengatasi terhadap } \\
\text { ancaman }\end{array}$ & $\begin{array}{c}\text { tidak rentan terhadap } \\
\text { ancaman }\end{array}$ \\
\hline
\end{tabular}

Diadopsi dari: (Chermack and Kasshanna, 2007)

Kemampuan analisis SWOT dalam mengidentifikasi berbagai faktor secara sistematis dapat digunakan untuk merumuskan strategi perusahaan (Rangkuti, 2009). Pada SWOT akan diperoleh 4 kebijakan yaitu SO (strategi kebijakan berbasis kekuatan dan peluang), ST (strategi kebijakan berbasis kekuatan dan hambatan/tantangan), WO (strategi kebijakan berbasis kelemahan dan peluang), dan WT (strategi kebijakan berbasis kelemahan dan tantangan/hambatan).

\section{UMKM}

Di Indonesia, UKM adalah tulang punggung ekonomi Indonesia. Jumlah UKM hingga 2011 mencapai sekitar 52 juta. UKM di Indonesia sangat penting bagi ekonomi karena menyumbang $60 \%$ dari PDB dan menampung 97\% tenaga kerja. Badan Pusat 
Statistik (BPS), mendefinisikan UMKM berdasarkan jumlah tenaga kerja. Usaha kecil memiliki jumlah tenaga kerja 5 s.d 19 orang, sedangkan usaha menengah memiliki tenaga kerja 20 s.d. 99 orang. Tabel 3 menjelaskan klasifikasi UMKM menurut Menegkop dan UKM.

Tabel 3 Tingkatan UKM menurut Menegkop dan UKM

\begin{tabular}{|c|c|c|c|}
\hline $\begin{array}{c}\text { Tingkatan } \\
\text { Usaha }\end{array}$ & Nilai Kekayaan & $\begin{array}{c}\text { Penjualan per } \\
\text { tahun }\end{array}$ & $\begin{array}{c}\text { Tenaga } \\
\text { kerja }\end{array}$ \\
\hline $\begin{array}{c}\text { Usaha Kecil } \\
\text { (UK) atau } \\
\begin{array}{c}\text { Usaha Mikro } \\
\text { (UMI) }\end{array}\end{array}$ & $\begin{array}{c}\text { termasuk tanah dan } \\
\text { bangunan usaha) }\end{array}$ & 200 Juta (Tidak 1 Miliar & $\begin{array}{c}\text { Antara 5 s/d } \\
19 \text { orang }\end{array}$ \\
\hline $\begin{array}{c}\text { Usaha } \\
\text { Menengah }\end{array}$ & $\begin{array}{c}\leq \text { Rp. 600 Juta (Tidak } \\
\text { termasuk tanah dan } \\
\text { bangunan usaha) }\end{array}$ & & $\begin{array}{c}\text { Antara 20 } \\
\text { s/d 99 orang }\end{array}$ \\
\hline
\end{tabular}

Sumber: Kementrian Menteri Negara Koperasi dan Usaha Kecil Menengah (Menegkop dan UKM)

Disisi lain, UMKM Malang Raya, telah berkontribusi kisaran 69,09\% (Rp 654,785 trilyun) terhadap PDRB (BPS, 2017). Demikian kontribusi usaha dan penyerapan tenaga kerja UMKM merupakan peran riil dalam menyelesaikan masalah perekonomian. Pengamatan lebih spesifik terhadap UMKM dapat dilihat pada Tabel 4, yang menunjukkan terjadinya peningkatan jumlah UMKM sebesar 15.91\% (20142015), 26.17\% (2015-2016), 58.03\% (2016-2017), dan 13.51\% (2017-2018). Peningkatan jumlah UMKM terbesar pada tahun 2016-2017 (58.03\%). Hal ini terkait dengan berbagai kebijakan pemerintah daerah Provinsi Jawa Timur antara lain implementasi pemberian dana hibah, pemberdayaan UMKM dan penghargaan UMKM. Pada tataran wilayah Jawa Timur, capaian jumlah UMKM sebesar 6.825.931 dengan penyerapan SDM sebesar 11.117.439 (Kinerja UMKM Jawa Timur, 2017).

TAHUN

Tabel 4. Perkembangan UMKM di Malang Raya Tahun 2014-2018

\begin{tabular}{|c|c|c|c|}
\hline \multirow[t]{2}{*}{ TAHUN } & \multicolumn{3}{|c|}{ INDIKATOR } \\
\hline & JUMLAH UMKM & $\begin{array}{c}\text { TENAGA } \\
\text { KERJA }\end{array}$ & $\begin{array}{l}\text { VOLUME } \\
\text { USAHA (Rp) }\end{array}$ \\
\hline 2014 & 27.918 Unit & 49.641 Orang & 9,356 Trilyun \\
\hline 2015 & 28.619 Unit & 54.741 Orang & 10,854 Trilyun \\
\hline 2016 & 23.396 Unit & 56.914 Orang & 21,50 Trilyun \\
\hline 2017 & 38.712 Unit & 58.420 Orang & 22,35 Trilyun \\
\hline 2018 & 39.145 Unit & 74.430 Orang & 26,29 Trilyun \\
\hline
\end{tabular}

Sumber: Diolah dari BPS Jawa Timur (2017)

Pada tabel 4, data 5 tahun 2014-2018 merupakan fenomena menarik untuk diamati. Periode 2016-2017 terjadi persentase peningkatan jumlah UMKM terbesar (58.03\%), tetapi justru terjadi peningkatan penyerapan SDM yang paling kecil $(2,65 \%)$, bersamaan dengan persentase peningkatan volume usaha terkecil pula (3.95\%). Dari data tersebut, tentunya perkembangan jumlah UMKM harus diimbangi dengan jumlah tenaga 
kerja berkualitas dan maksimalisasi volume usaha yang signifikan. Hermawati and Mas (2016a; b) menyatakan bahwa SDM merupakan aset utama bagi organisasi. SDM merupakan komoditas yang mampu melakukan pelayanan terhadap orang lain. Sehingga dapat dikatakan bahwa strategi berbasis human resource merupakan nilai tambah yang mutlak dibutuhkan SDM pada UMKM.

Ditegaskan Hermawati and Mas (2016a); Purnamasari, Suci and Handini (2013); Suci and Priyono (2013); Suci (2013, 2009), solusi yang ditempuh dalam mengatasi lemahnya "volume usaha" adalah dengan revitalisasi human resources strategy dengan cara optimalisasi employe performance, human resources trainning \& development, human resources planning.

Temuan Hermawati and Mas (2016a; b) bahwa eksistensi UMKM, peluang UMKM maupun upaya UMKM dalam menghadapi tantangan era pasar global, direkomendasikan agar difokuskan pada optimalisasi kinerja SDM. Prospek berkembangnya UMKM tidak hanya dengan implementasi quality of work life dan transglobal leadership, namun melalui penguatan aspek terintegrasi antara transglobal leadership, quality of work life, keterlibatan pekerjaan yang bermuara pada kinerja karyawan dan hilirisasi kinerja organisasi UMKM.

\section{METODE}

SWOT dapat menjadi alat yang digdaya dan mampu mengeksplorasi kemungkinan-kemungkinan perencanaan strategi baru maupun memulai program yang baru (Chermack and Kasshanna, 2007). Chermack and Kasshanna (2007) menguraikan tahapan SWOT yang terangkum dalam gambar 1.

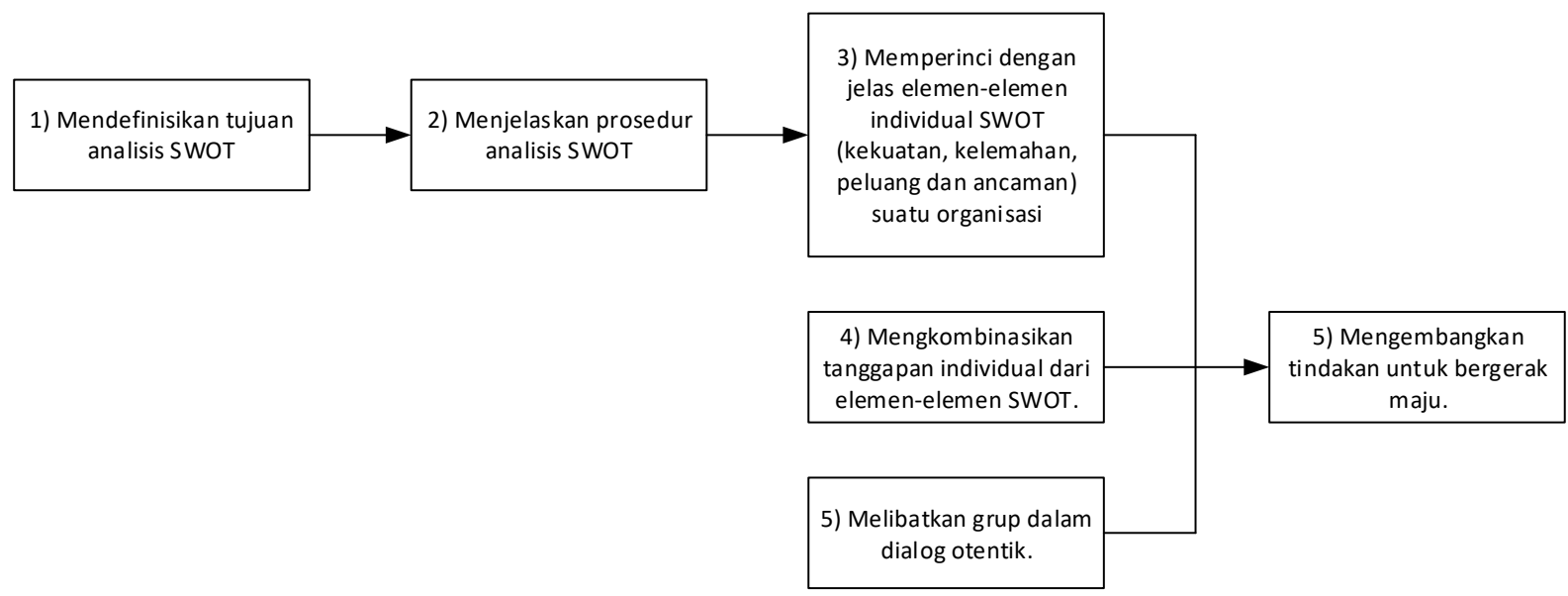

Gambar 1. Tahapan SWOT

Diadopsi dari Chermack and Kasshanna (2007).

Langkah Satu: Tentukan Tujuannya

Langkah pertama dalam SWOT adalah menentukan tujuan eksplisit yang telah disetujui oleh semua peserta tim penganalis dalam proses perencanaan strategi. Pendefinisian ini harus dilakukan dengan hati-hati. Hal ini karena jika terjadi kegagalan dalam identifikasi tujuan maka perencanaan sumber daya dapat menjadi tidak efisien dan sia-sia. 
Langkah Dua: Jelaskan Prosesnya kepada Peserta Tim Penganalis

Setelah tujuan telah ditetapkan dan disetujui, langkah kedua yaitu menjelaskan pada peserta Tim Penganalis tentang prosedur analisis SWOT. Pada tahap ini, perencanaan kegiatan di masa depan harus diklarifikasi dan dijadwalkan dengan jelas dan disetujui oleh semua partisipan.

Langkah Tiga: Memperoleh Kontribusi Individu

Langkah ketiga menampilkan aspek-aspek analisis SWOT dengan meminta para peserta mengisi matriks kekuatan, kelemahan, peluang, dan ancaman yang saat ini dihadapi organisasi.

Langkah Empat: Merangkum Kontribusi semua peserta

Setelah kontribusi individu telah diperoleh, selanjutnya mengumpulkan tanggapan-tanggapan tersebut menjadi satu gambaran besar yang berisi semua perspektif tentang kekuatan, kelemahan, peluang, dan ancaman organisasi.

Langkah Kelima: Memfasilitasi Dialog Strategis

Memfasilitasi dialog strategis dapat menjadi bagian yang paling potensial dalam analisis SWOT dalam menciptakan perubahan berdasarkan sudut pandang peserta Tim Penganalis. Sangat penting untuk mengidentifikasi kekuatan yang bisa dipandang sebagai kelemahan dan peluang yang bisa jadi mengandung ancaman tersembunyi. Selain itu, dialog strategis dapat merencanakan berbagai tindakan yang disesuaikan tujuan yang ingin dicapai atau keadaan akhir yang ingin dicapai. Karena dari SWOT, organisasi dapat memanfaatkan kekuatan, mengatasi kelemahan, mengambil keuntungan penuh dari peluang, dan meminimalkan dampak ancaman, maka SWOT dapat mengidentifikasi masalah yang dianggap kunci bagi kinerja organisasi saat ini dan di masa yang akan datang.

\section{HASIL DAN PEMBAHASAN}

Berdasarkan data dari Dinas Koperasi dan UMKM (2016) se-Malang Raya, jumlah populasi seluruh karyawan UMKM adalah sebesar 2.790. Penentuan ukuran sampel dengan menggunakan Rumus Slovin pada presisi 5\% Perhitungan dalam area sampling ini ditetapkan yaitu 846 orang karyawan menjadi sampel yang diambil dari UMKM berdasarkan atas wilayah kota Malang. UMKM di Kota Malang yang digunakan sebagai sampel penelitian ini adalah (1) Ebe-Pembuatan tas sekolah, (2) Berry Sablon dan konveksiSablon kaos dan jahit, (3) Arema kaos dan sablon-Konveksi kaos dan sablon, (4) K.P.W 33Pupuk cair organik dan probiotik, (5) La Russo-Konveksi hem / baju La Russo, (6) CV. Putra Setia-Bakso jamur, (7) Mirasa-Mebel, (8) Ampera-Krupuk kedelai mentah, (9) Saha Collection-Kerajinan dari akrylik, (10) Kingkong-Industri makanan kecil, (11) Candi Jago, (12) Coban Ciblungan, (13) Taman Dolan Batu, (14) Wisma Tumapel, (15) Taman Merbabu, (16) Museum Musik Indonesia, (17) Seni ukir antik-Meubel, (18) AlamindoJamu toga, (19) Anggengo-Kue Bakpia Kering, dan (20) llani-Abon jamur tiram.

\section{Analisis SWOT}

Pada masing-masing UMKM dilakukan penyebaran kuesioner kemudian dihitung nilai rata-rata dari setiap item. Selanjutnya dengan data berupa rata-rata dari 20 UMKM, dilakukan analisis SWOT. Hasil penilaian terhadap faktor internal UMKM Kota Malang disajikan dalam bentuk Gambar 2, sementara hasil penilaian terhadap faktor eksternal UMKM Kota Malang disajikan dalam bentuk Gambar 3. 

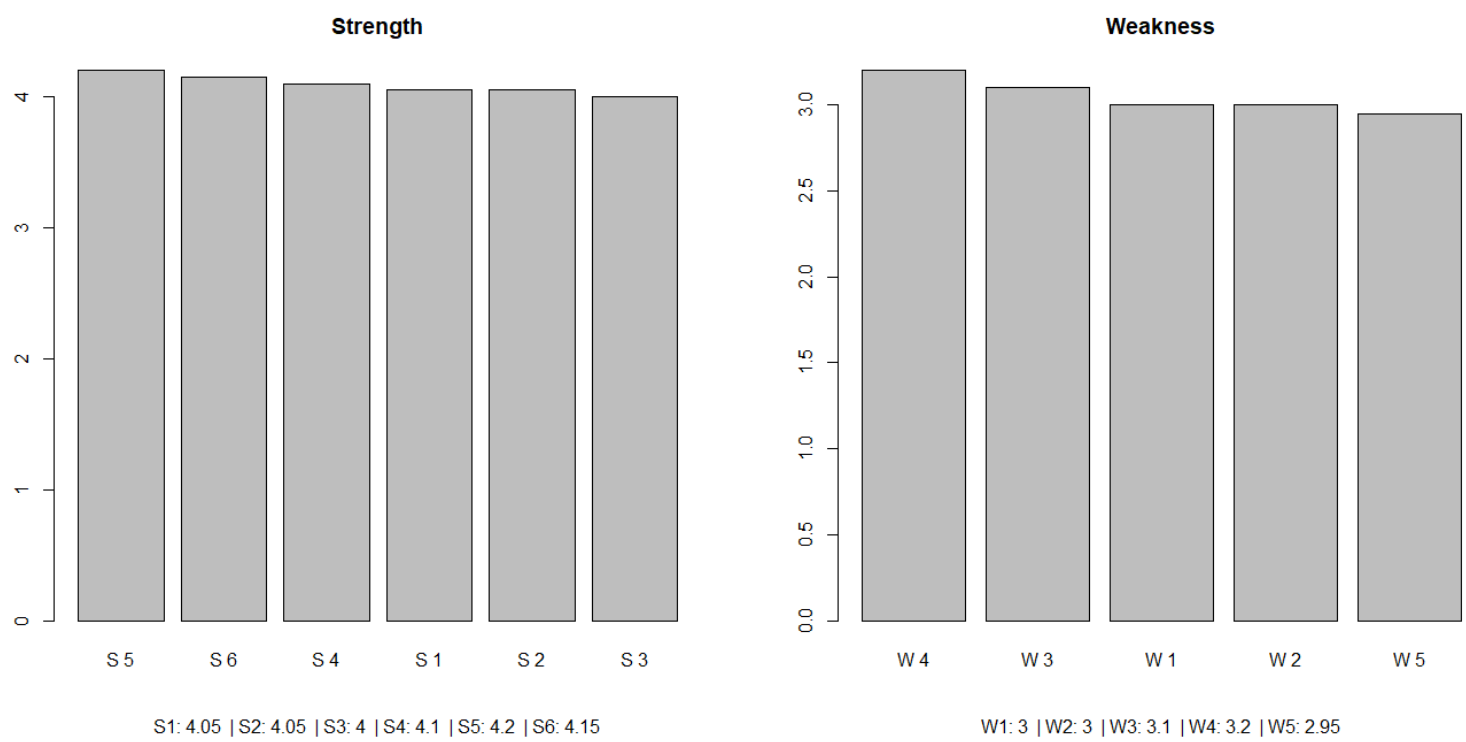

Gambar 2. Faktor Internal Kota Malang

Keterangan:

S1: Kualitas produk

S2: Brand image

S3: Harga

S4: Lokasi

S5: Pelayanan

S6: Pelanggan tetap
W1: Overproduksi

W2: Ruang lingkup distribusi

W3: Kegiatan promosi

W4: Kualitas SDM

W5: Kekurangan modal untuk pengembangan bisnis

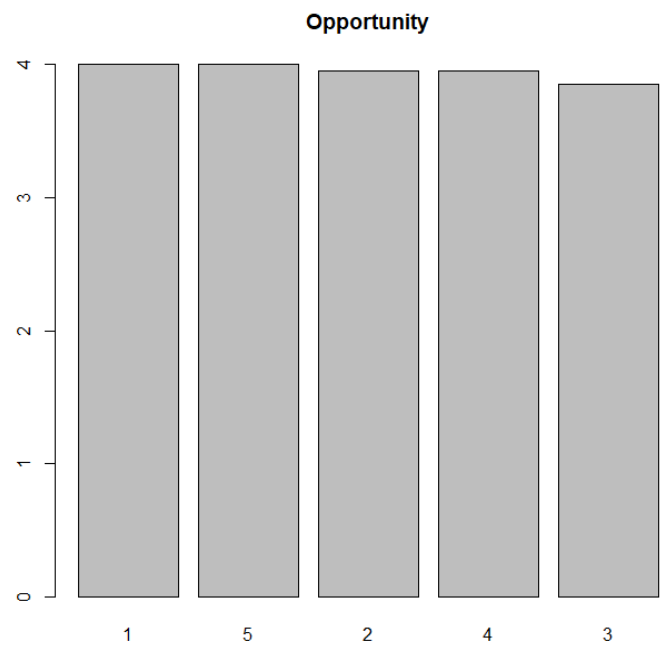

01: 4 | 02: 3.95 |03: $3.85|04: 3.95| 05: 4$

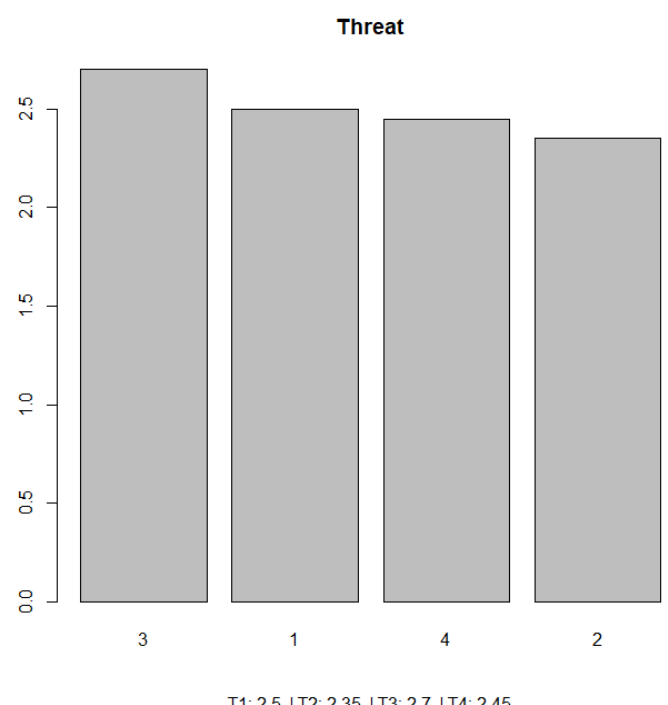

T1: 2.5 |T2: 2.35 | T3: 2.7 | T4: 2.45

Gambar 3. Faktor Eksternal Kota Malang 
Keterangan:

O1: Oleh-oleh khas daerah

O2: Pangsa pasar

O3: Hubungan baik dengan sesama pengusaha

O4: Kemajuan teknologi

O5: Bahan baku
T1: Pergeseran konsumsi masyarakat

T2: Ruang lingkup distribusi pesaing

T3: Pesaing pendatang baru

T4: Harga pesaing

Berdasarkan Gambar 2, indikator Strength yang paling tinggi adalah S5 (Pelayanan) yaitu sebesar 4.20. Hal ini dapat diartikan bahwa Pelayanan yang ditawarkan UMKM di Kota Malang sudah sesuai dengan ekspektasi pelanggan. Sementara itu, indikator Weakness yang paling tinggi adalah W4 (Kualitas Sumber Daya Manusia), yaitu sebesar 3.20. Hal ini dapat diartikan bahwa permasalahan kurangnya skill dan pengetahuan SDM merupakan masalah internal yang perlu diperhatikan oleh UMKM di Kota Malang.

Berdasarkan Gambar 3, indikator Opportunity yang paling tinggi adalah O1 (Oleholeh khas daerah) dan O5 (Bahan Baku) yaitu sebesar 4. Hal ini dapat diartikan bahwa oleholeh khas daerah sangat diminati pelanggan serta bahan baku yang dibutuhkan UMKM di Kota Malang melimpah. Sementara itu, indikator Threat yang paling tinggi adalah T3 (Pesaing pendatang baru), yaitu sebesar 2.3. Hal ini dapat diartikan bahwa pesaing pendatang baru cukup mengancam UMKM yang sudah ada lebih dulu di Kota Malang.

Total skor faktor internal dan eksternal UMKM di Kota Malang disajikan dalam Tabel 5.

Tabel 5. Total Skor Faktor Internal dan Eskternal Kota Malang

\begin{tabular}{|l|c|l|c|}
\hline Internal & Skor & Eksternal & Skor \\
\hline Strengh & 4.0917 & Opportunity & 3.9591 \\
\hline Weakness & -3.0312 & Threat & -2.5150 \\
\hline Total & 1.0604 & Total & 1.4441 \\
\hline
\end{tabular}

Berdasarkan Tabel 5 diperoleh bahwa skor Strength lebih besar daripada skor Weakness sehingga diperoleh total skor dengan tanda positif. Selain itu, skor Opportunity lebih besar daripada skor Threat sehingga diperoleh total skor dengan tanda positif.

Setelah diperoleh skor, maka dapat dibuat plot SWOT dengan titik A, B, C, dan D seperti pada Gambar 4. 


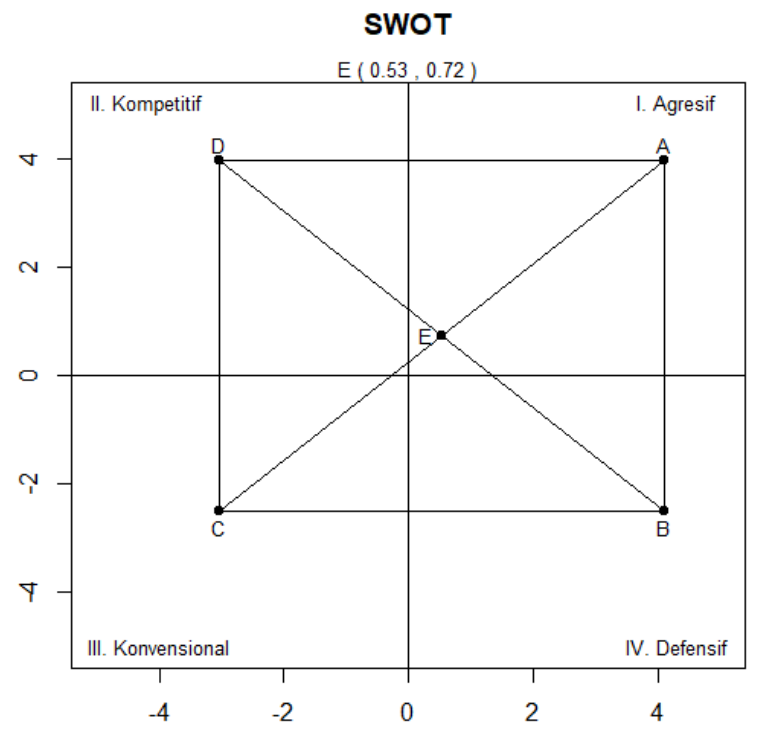

Gambar 4. Plot SWOT Kota Malang

Untuk menentukan strategi dapat dilihat melalui lokasi titik potong A, B, C, dan D, yaitu titik E. Berdasarkan Gambar 4, titik E berada kuadran I. Dapat disimpulkan bahwa kuadran yang paling luas adalah kuadran I. Dengan demikian, analisis SWOT terhadap UMKM di Kota Malang menunjukkan posisi yang bagus, sehingga dapat diterapkan strategi SO.

Cara lain untuk menentukan strategi adalah dengan menghitung luas setiap kuadran yang dibatasi oleh titik A, B, C, dan D. Selanjutnya dipilih kuadran yang paling luas sebagai strategi. Hasil perhitungan luas pada analisis SWOT di Kota Malang dimuat dalam Tabel 6 berikut ini.

Tabel 6 Luas Wilayah Kuadran Kota Malang

\begin{tabular}{|l|l|l|}
\hline Kuadran & Luas & Rank \\
\hline I & 16.19945 & 1 \\
\hline II & 12.00082 & 2 \\
\hline III & 7.623468 & 4 \\
\hline IV & 10.29063 & 3 \\
\hline
\end{tabular}

\section{SIMPULAN}

Penelitian ini bertujuan untuk mengidentifikasi strategi yang sesuai dengan implementasi SWOT Hasil menunjukkan indikator Strength yang paling tinggi adalah S5 (Pelayanan). Hal ini dapat diartikan bahwa Pelayanan yang ditawarkan UMKM di Kota Malang sudah sesuai dengan ekspektasi pelanggan. Sementara itu, indikator Weakness yang paling tinggi adalah W4 (Kualitas Sumber Daya Manusia). Hal ini dapat diartikan bahwa permasalahan kurangnya skill dan pengetahuan SDM merupakan masalah internal yang perlu diperhatikan oleh UMKM di Kota Malang. Kemudian indikator Opportunity yang 
paling tinggi adalah O1 (Oleh-oleh khas daerah) dan O5 (Bahan Baku). Hal ini dapat diartikan bahwa oleh-oleh khas daerah sangat diminati pelanggan serta bahan baku yang dibutuhkan UMKM di Kota Malang melimpah. Sementara itu, indikator Threat yang paling tinggi adalah T3 (Pesaing pendatang baru). Hal ini dapat diartikan bahwa pesaing pendatang baru cukup mengancam UMKM yang sudah ada lebih dulu di Kota Malang. Kemudian untuk Titik E yang merupakan perpotongan titik A, B, C, dan D berada kuadran I (Strategi agresif). Dengan demikian, analisis SWOT terhadap UMKM di Kota Malang menunjukkan posisi yang bagus, sehingga dapat diterapkan strategi SO.

Keterbatasan pada riset ini adalah analisis yang hanya dilakukan pada satu kota yang mungkin akan berbeda hasilnya jika diterapkan pada kota yang lain di Jawa Timur maupun di Indonesia. Sehingga hasil penelitian ini masih belum bisa menggeneralisasi kota lainnya. Selanjutnya perlu penelitian lebih lanjut untuk implementasi pada kota lainnya sebagai agenda penelitian di masa yang akan datang. Penelitian selanjutnya juga dapat menggabungkan analisis SWOT dan metode analisis keputusan seperti AHP dan ANP, sehingga perumusan strategi terbaik untuk UMKM dapat teridentifikasi.

\section{REFERENSI}

Amanatidou, E., 2014. Beyond the veil - The real value of foresight. Technological Forecasting and Social Change, 87, pp.274-291.

Anggarani, D., Mas'ud, M.H. and Zulkifli, 2017. Model Pengembangan Usaha Kecil Menengah Produk Unggulan Berbasis Wilayah di Kota Batu. In: Prosiding Widyagama National Conference on Economics and Business. pp.229-237.

Cengiz Toklu, M., Erdem, M.B. and Taşkın, H., 2016. A fuzzy sequential model for realization of strategic planning in manufacturing firms. Computers and Industrial Engineering, 102, pp.512-519.

Chermack, T.J. and Kasshanna, B.K., 2007. The use and misuse of swot analysis and implications for hrd professionals. Human Resource Development International, 10(4), pp.383-399.

David, F.R., 2009. Manajemen strategis konsep. Jakarta: Salemba Empat.

Eko Nurmianto, Arman Hakim Nasution and Syafril Syafar, 2004. Perumusan Strategi Kemitraan Menggunakan Metode AHP dan SWOT (Studi Kasus pada Kemitraan PT. INKA dengan Industri Kecil Menengah di Wilayah Karesidenan Madiun). Jurnal Teknik Industri, 6, pp.47-60.

Erdil, A. and Erbıyık, H., 2015. Selection Strategy via Analytic Hierarchy Process: An Application for a Small Enterprise in Milk Sector. In: World Conference on Technology, Innovation and Entrepreneurship Selection. pp.2618-2628.

Fahmy Salama, K., Luzzatto, D., Sianesi, A. and Towill, D.R., 2009. The value of auditing supply chains. International Journal of Production Economics, 119(1), pp.34-45.

Hadjimanolis, A., 1999. Barriers to innovation for SMEs in a small less developed country (Cyprus). Technovation, 19(9), pp.561-570.

Hermawati, A. and Mas, N., 2016a. Mediation Effect of Quality of Worklife, Job Involvement, and Organizational Citizenship Behavior (Case Study in The Most Outstanding Cooperatives in East Java Province). International Journal of Law and Management, 31(2), pp.228-239.

Hermawati, A. and Mas, N., 2016b. Transglobal Leadership, Quality of Work Life, and Employee Performance in Cooperatives in East Java, Indonesia. International journal 
of Business Management , 1(1), pp.1-8.

Purnamasari, R., Suci, R.P. and Handini, D.P., 2013. Strategi Keuangan Matriks Sebagai Alat Bantu Keputusan Investasi dan Pembiayaan. Jurnal Manajemen dan Akuntansi, 2(2), pp.95-107.

Rangkuti, F., 2009. Analisis SWOT Teknik Membedah Kasus Bisnis. Jakarta: Gramedia Pustaka Utama.

Subramanian, N. and Ramanathan, R., 2012. A review of applications of Analytic Hierarchy Process in operations management. International Journal of Production Economics, 138(2), pp.215-241.

Suci, R.P., 2009. Peningkatan Kinerja Melalui Orientasi Kewirausahaan, Kemampuan Manajemen, dan Strategi Bisnis (Studi pada Industri Kecil Menengah Bordir di Jawa Timur). Jurnal Manajemen dan Kewirausahaan, 11, p.pp.46-58.

Suci, R.P., 2013. Analysis Strategy for Small and Medium Business Development Policy Gresik District in East Java. IOSR Journal of Business and Management, 8(1), pp.19.

Suci, R.P. and Priyono, 2013. Analysis Of Small Industries Development Strategy Craft " Cindogo " ( Case Study Center Industry In The Small Village Crafts Cindogo District Tapen Bondowoso ). Developing Country Studies, 3(11), pp.19-30. 